\title{
Dynamic Analysis of Steel Platforms When Subjected to Mechanical Equipment-Induced Vibrations
}

\author{
José Guilherme S. da Silva ${ }^{1,2}$, Ana Cristina C. F. Sieira ${ }^{1,2}$, Luís A. P. Simões da Silva ${ }^{3}$ and Bruno D. Rimola ${ }^{2}$ \\ 1. Structural Engineering Department (ESTR), State University of Rio de Janeiro (UERJ), Rio de Janeiro 20550-900, Brazil \\ 2. Civil Engineering Post-graduate Programme (PGECIV), State University of Rio de Janeiro (UERJ), Rio de Janeiro 20550-900, \\ Brazil \\ 3. Civil Engineering Department, University of Coimbra, Coimbra 3030-788, Portugal
}

\begin{abstract}
The competitive trends of the world market have long been forcing structural engineers to develop minimum weight and labour cost solutions. A direct consequence of this new design trend has been a considerable increase in problems related to undesired floor vibrations. For this reason, structural floor systems can become vulnerable to excessive vibrations that are produced by, for example, impacts due to mechanical equipment (e.g., rotating machinery). This study investigates the dynamic behaviour of a production platform constructed of steel and located in the Santos Basin (Merluza field), São Paulo/SP, Brazil, when subjected to impacts produced by mechanical equipment (rotating machinery). The structural model consists of two steel decks with a total area of $1,915 \mathrm{~m}^{2}$ (upper deck: $445 \mathrm{~m}^{2}$, lower deck: 1,470 $\mathrm{m}^{2}$ ) and supported by piles. A numerical analysis is performed to assess the dynamic impacts on the deck structure originating from the electrical generators and compressors. Based on the peak acceleration values obtained for the structure steady-state response, it is possible to evaluate the structural model performance in terms of human comfort, the maximum tolerances of the mechanical equipment and the vibration serviceability limit states of the structure.
\end{abstract}

Key words: Dynamic analysis, steel structures, production platforms, human comfort, structural behaviour, computational modelling.

\section{Introduction}

Structural engineers have long been attempting to develop solutions using the full potential of composite materials. At this point, there is no doubt that the progress of structural solutions is directly related to an increase in the knowledge of materials science.

However, competitive trends of the globalized market continuously force structural engineers to develop minimum life cycle cost solutions. In the field of floor systems, a consequence of this design trend is a considerable increase in problems related to undesired floor vibrations. Structural floor systems may become vulnerable to excessive vibrations that are produced by, for example, impacts due to

Corresponding author: José Guilherme S. da Silva, professor, research fields: structural dynamics; vibration analysis; dynamic experimental monitoring; steel and steel-concrete structures; numerical modelling. mechanical equipment (e.g., rotating machinery) $[1,2]$.

This study investigates the dynamic behaviour of an oil production platform constructed of steel and located in the Santos Basin, São Paulo, Brazil. The structural model consists of two steel decks with a total area of $1,915 \mathrm{~m}^{2}$ (upper deck: $445 \mathrm{~m}^{2}$, and lower deck: $1,470 \mathrm{~m}^{2}$ ) supported by vertical sections made of tubular steel members (steel jacket) and piled into the seabed. A variety of mechanical equipment related to electrical generators and compressors was located on the steel decks of the structural model $[1,2]$.

The soil representation was based on Winkler's theory [3]. This theory simulates the soil behaviour as a group of independent springs governed by a linear-elastic model. In Winkler's model, soil stiffness is considered to be the required pressure to produce a unit displacement [3]. 
The proposed numeric-computational model that was developed for the oil production platform dynamic analysis adopted the usual mesh refinement techniques that are present in finite element method simulations implemented in the GTSTRUDL (a structural design and analysis software) program [4]. In this finite element model, the floor steel girders and columns were represented by three-dimensional beam elements, where flexural and torsion effects were considered. The steel decks were represented by shell finite elements. In this investigation, it was assumed that both structural elements (i.e., steel beams and steel deck plates) interact with a completely elastic behaviour.

The structural model dynamic response was determined through an analysis of its natural frequencies and peak accelerations. The results of the dynamic analysis were obtained from an extensive numerical study based on the finite element method using the GTSTRUDL program [4]. In this investigation, the dynamic loadings coming from the rotating machinery (electrical generators and compressors) were applied to the steel decks of the structural system.

A numerical analysis was performed to obtain the dynamic impacts on the deck structure coming from the electrical generators and compressors. Based on the peak acceleration values obtained on the structure steady-state response, it was possible to evaluate the structural model performance in terms of human comfort, the maximum tolerances of the mechanical equipment and the vibration serviceability limit states of the structural system based on the design code recommendations [5-9].

\section{Vibration Analysis of Steel Floors}

In addition to the evaluation of the structural systems behaviour when submitted to dynamic loads, the causes and effects of vibration on humans have been the subject of many studies and experiments given that such vibrations affect individuals in different ways, causing discomfort, health problems, reduced ability to concentrate and reduced efficiency at work. Sickness can even result in the case of vibrations of very low frequencies. Having this thought in mind, the authors highlighted some relevant research works in the following paragraphs.

Srinivasulu and Vaidyanathan [10] presented the principles of the analysis, design and construction of different types of machines. The authors investigated several factors during the design of machine foundations to obtain the optimum solution, leading to improved operation and reducing the undesirable effects of vibrations on the structure.

Bachmann et al. [11] studied the procedures for the analysis of structures under dynamic loads coming from machines, including machines with rotating parts. The authors also examined the effects of machinery-induced vibrations in structures as well as measures to avoid such problems. Their study also included acceptance criteria, both from the perspective of the structure and that of human comfort.

Zhou and Shi [12] considered that eliminating the vibration of rotating machinery is an important engineering problem. They presented a detailed review of the developed research that addresses the active balancing of rotors in real time, the active control of the vibration of rotating machinery and the dynamic modelling and analysis techniques for rotating systems. The authors reported that the major problem with the scheme of actively controlling vibration is that a limited number of actuators would be required to control an unlimited number of vibration modes.

Silva [13] has established that the concept of human vibration discomfort can be difficult. There are several factors that can influence the subjective sensation of discomfort, such as the socio-cultural background, the type of activity performed, the person's psychological state at the time of the event, environmental factors, noise, etc. It is not a simple matter to simulate these conditions in the laboratory to reduce the variability of 
individual responses. Thus, the limit of the comfort of individuals subjected to vibration can be regarded as a rather subjective measure, generating certain controversy as to the acceptable values of the accelerations imposed.

Milet [14] has discussed the basic concepts of the dynamic analysis of machine foundations, based on the investigation on the certain analytical strategies and numerical methods available for design. In this research work, design recommendations were presented and discussed.

Souza et al. [15] developed a prototype that allows for the detection of possible structural effects that are caused by the resonance phenomenon as well as for comparisons to be made with more complex structural systems by analysing a simple system based on an unbalanced rotor. Furthermore, the experiment is practical, simple and can serve as an analytical tool in the classroom, thus giving a better understanding of phenomena related to vibration.

Assunção [16] addressed the issues and the most important conditions for the dynamic analysis of frame structures, where equipment was allocated for industrial processes. In this investigation, the author developed a study related to the primary causes of dynamic actions coming from industrial equipment and examined a framed structure supporting an unbalanced machine.

Genta [17] emphasizes that dynamic problems, which in the past were accounted for by simple overdesign of the relevant elements, must now be studied in detail, and dynamic design is increasingly the most part of the design of many machines. On the other hand, all these aspects compel designers to deal in more detail with the dynamic behaviour of structures and machines.

\section{Modelling of the Dynamic Loading}

Knowledge of the dynamic behaviour of rotors of rotating machinery, even in the design phase, has become an increasingly crucial factor, considering that it is not desirable to take corrective actions after the beginning of activities. Delays caused by corrective measures are highly costly, and the financial impact of delayed production is orders of magnitude higher than a slightly more expressive solution in the design phase.

According to Dias Junior [18], among the several factors that contribute to the transmission of rotational energy to the vibratory movements of the machine, the most critical is undoubtedly the unbalance of the rotor. The rotor is the rotating part of a machine or engine and may comprise coupled elements, such as disks, generators, gears, etc. If an unbalance is present, the force that acts at the rotor centroid pushes the shaft out of the line joining the two bearings, forcing the shaft to rotate in a stressed state. This movement is referred to as precession movement [18].

Considering an unbalanced load spinning around an axis, the procedure for obtaining the global dynamic force acting on a plane is to apply the force in two orthogonal directions. One of these forces is applied in the horizontal direction with the angle phase $\phi$ equal to zero, and the other force is in the vertical direction with the angle phase $\phi$ equal to $1 / 4$ of the period of the vibration of the unbalanced force.

Thus, as time increases, there is a variation of the two forces, such that the composition (horizontal and vertical directions) results in a harmonic unbalanced force in which one component will be multiplied by $\sin (\Omega t)$ and the other by $\sin (\Omega t+\pi / 2)$. This way, when one harmonic component presents maximum values, the other is equal to zero, and vice versa.

The value of the dynamic force is obtained by the vector sum of the components in the vertical and horizontal directions, as presented in Eq. (1), where $P_{0}$ is the dynamic loading amplitude, calculated based on the total mass in rotation, the equipment frequency $\Omega$ and the equipment balance quality grade $G(G=R \Omega$ : for the rotors of electric motors, the value of $R \Omega$ was set to $0.0025 \mathrm{~m} / \mathrm{s}$ ). To perform the dynamic analysis of the oil production platform developed in this 
investigation, the data in Tables 1 and 2 were used. Fig. 1 shows the design of the equipment.

$$
P=P_{0} \sin (\Omega t)+P_{0} \sin \left(\Omega t+\frac{\pi}{2}\right)
$$

The dynamic loading modelling considered two components related to the vertical and horizontal directions. Tables 1 and 2 show the dynamic loads applied on the steel deck of the structure. These settings of the model were properly combined to better represent the dynamic excitation induced by the equipment on the structure $[1,2]$.

\section{Investigated Structural Model}

The investigated structural system is related to an oil production platform constructed of steel and located in São Paulo/SP, Brazil. The structure is supported by vertical sections constructed of tubular steel members (steel jacket), piled into the seabed by steel piles and consists of two steel decks with an area of $1,915 \mathrm{~m}^{2}$ (upper deck: $445 \mathrm{~m}^{2}$, and lower deck:

Table 1 Mechanical equipment data.

\begin{tabular}{ll}
\hline Equipment data & \\
\hline Protective cover & $1.2 \mathrm{kN}$ \\
Coupling & $5.3 \mathrm{kN}$ \\
Gear unit & $37.5 \mathrm{kN}$ \\
Motor swing & $15 \mathrm{kN}$ \\
Rotor weight & $10.8 \mathrm{kN}$ \\
Input frequency & $30 \mathrm{~Hz}$ \\
Output frequency & $0.94 \mathrm{~Hz}$ \\
\hline
\end{tabular}

Table 2: Dynamic actions related to the equipment.

\begin{tabular}{lllll}
\hline Equipment & $\begin{array}{l}\text { Weight } \\
(\mathrm{kN})\end{array}$ & $\begin{array}{l}\text { Frequency } \\
(\mathrm{rad} / \mathrm{s})\end{array}$ & $\begin{array}{l}\text { Balance } \\
\text { quality grade } \\
R \omega(\mathrm{m} / \mathrm{s})\end{array}$ & $P_{0}(\mathrm{kN})$ \\
\hline Rotor & 10.80 & 188.49 & 0.0025 & 0.51 \\
Gear & 18.75 & 6.03 & 0.0025 & 0.028 \\
\hline
\end{tabular}

Fig. 1 Driving unit (motor, coupling and gear).

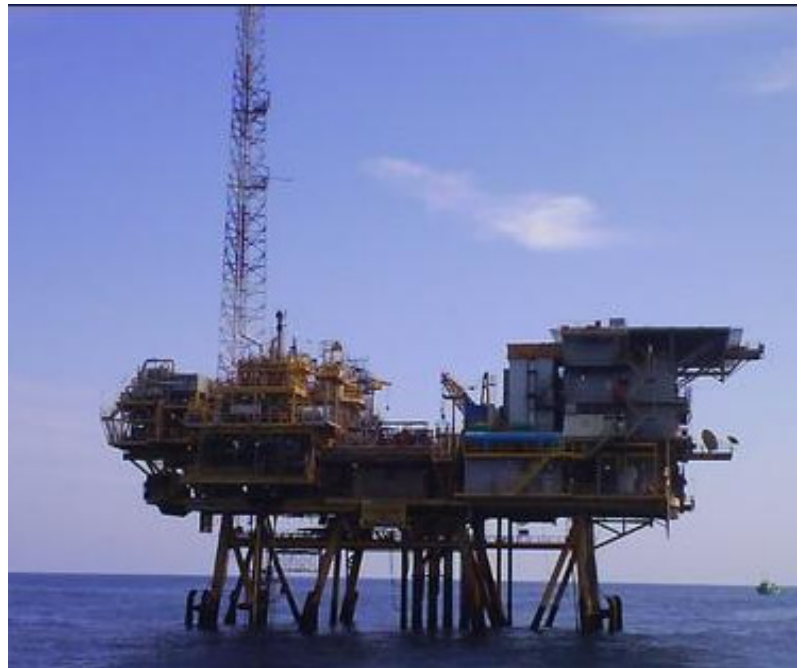

Fig. 2 Investigated structural model.

$1,470 \mathrm{~m}^{2}$. The structural model is formed by steel beams and columns and also steel deck plates, as presented in Fig. 2. This structural system is constituted by a large number of structural elements with very different geometrical characteristics [1]. A Young's modulus equal to $2.05 \times 10^{5} \mathrm{MPa}$ was adopted for the steel beams, columns and decks.

\section{Finite Element Modelling}

The proposed computational model, developed for the structural system dynamic analysis, adopted the usual mesh refinement techniques present in finite element method simulations as implemented in the GTSTRUDL program [4]. In this computational model, floor steel girders and columns were represented by a three-dimensional beam element with tension, compression, torsion and bending capabilities. The element had six degrees of freedom at each node: translations in the nodal $\mathrm{x}, \mathrm{y}$, and $\mathrm{z}$ directions and rotations about the $\mathrm{x}, \mathrm{y}$, and $\mathrm{z}$-axes. The steel deck plates were represented by shell finite elements [4].

In this investigation, both structural elements (i.e., the steel beams and steel deck plates) were assumed to have total interaction with an elastic behaviour. The finite element model had 1,824 nodes, 3,079 three-dimensional beam elements, 509 shell elements and 10,872 degrees of freedom (Fig. 3). 

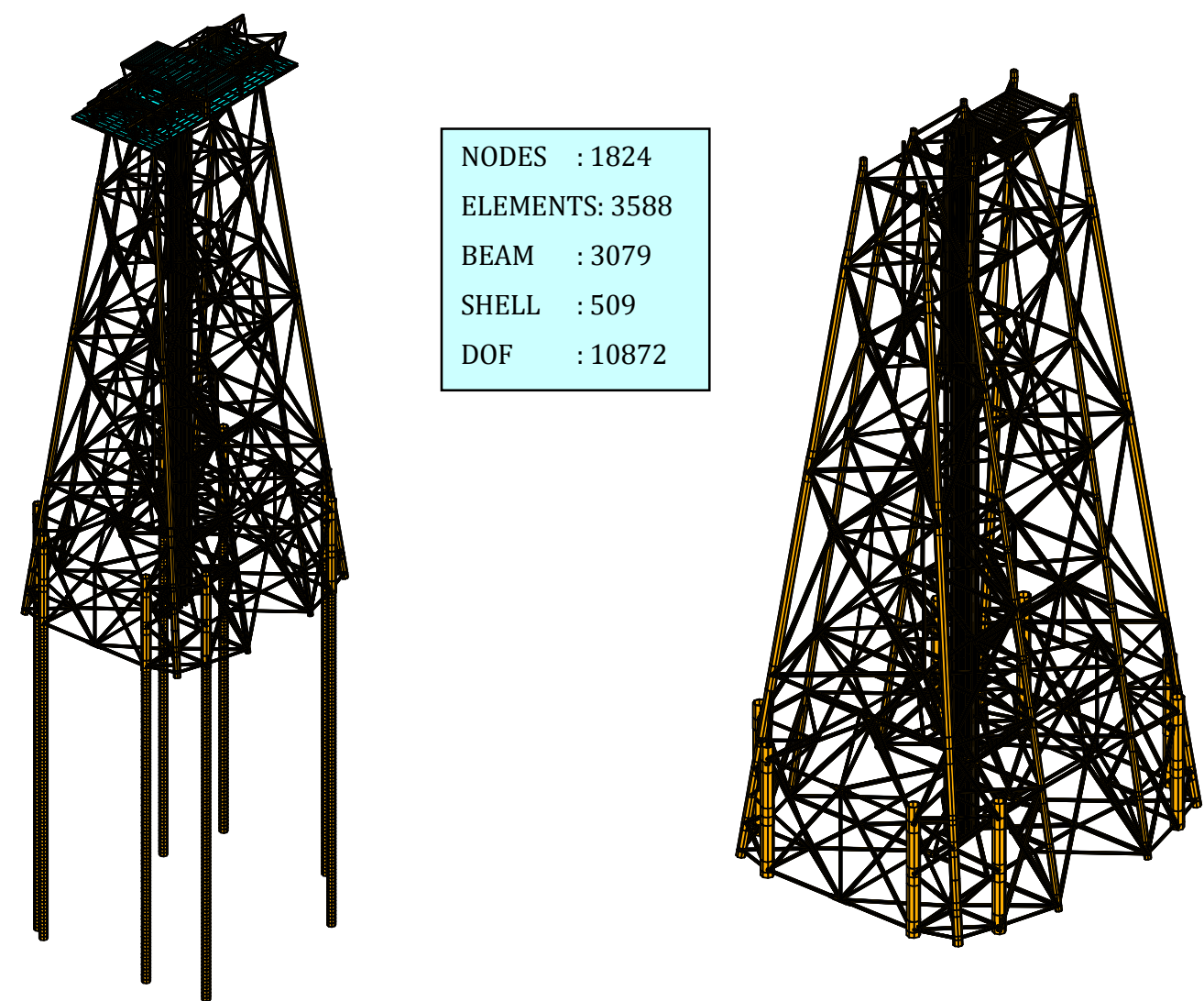

Fig. 3 Finite element model: production platform with steel jacket and piles.

The soil data were obtained using three boreholes (SPT (standard penetration tests)) at a depth varying from $43.5 \mathrm{~m}$ to $178.3 \mathrm{~m}$. The boreholes gave the geotechnical profile definition that was adopted in the finite element model $[1,2]$. The characterization and resistance tests that were performed in the laboratory provided the specific weight, friction angle and cohesion values presented in [1,2].

When the study of half-buried columns is considered, the usual methodology for the formulation of the soil-structure interaction problem utilizes the reaction coefficient concept, originally proposed by Winkler [3]. In the case of laterally loaded piles, the analysis procedure based on Winkler [3] is analogous to that used for shallow foundations.

The soil behaviour is simulated by a group of independent springs governed by a linear-elastic model. The foundation applies a reaction in the column normal direction that is proportional to the column deflection. Considering the subsoil geotechnical profile $[1,2]$ and using the analysis procedure based on the Winkler model [3], the horizontal reaction coefficients on the piles were determined as a function of the type of the soil [19]. Based on the values of the horizontal reaction coefficients, the foundation stiffness parameters values were calculated [3, 19]. This way, the foundation stiffness parameters values were used to determine the spring's stiffness used in the finite element model to simulate the soil behaviour. The spring elements that simulate the soil were discretized based on a range of length equal to $1 \mathrm{~m}$ and placed at the transversal direction of the pile section axis.

\section{Natural Frequencies and Mode Shapes}

The natural frequencies and vibration modes were determined with the aid of the finite element method, based on numerical simulations [4]; as presented in Table 3. On the other hand, the mode shapes associated to selected five natural frequencies of the 
Table 3 Production platform natural frequencies.

\begin{tabular}{llll}
\hline \multicolumn{2}{l}{ Frequencies $f_{0 i}(\mathrm{~Hz})$} & \multicolumn{2}{l}{ Structural system vibration modes } \\
\hline$f_{01}$ & 0.67 & Mode 1 & \\
$f_{02}$ & 0.71 & Mode 2 & Vibration modes with predominance of the steel jacket system \\
$f_{03}$ & 1.20 & Mode 3 & \\
$f_{08}$ & 1.99 & Mode 8 & \\
$f_{17}$ & 2.61 & Mode 17 & Vibration modes with predominance of the steel deck displacements \\
$f_{49}$ & 4.14 & Mode 49 & \\
\hline
\end{tabular}

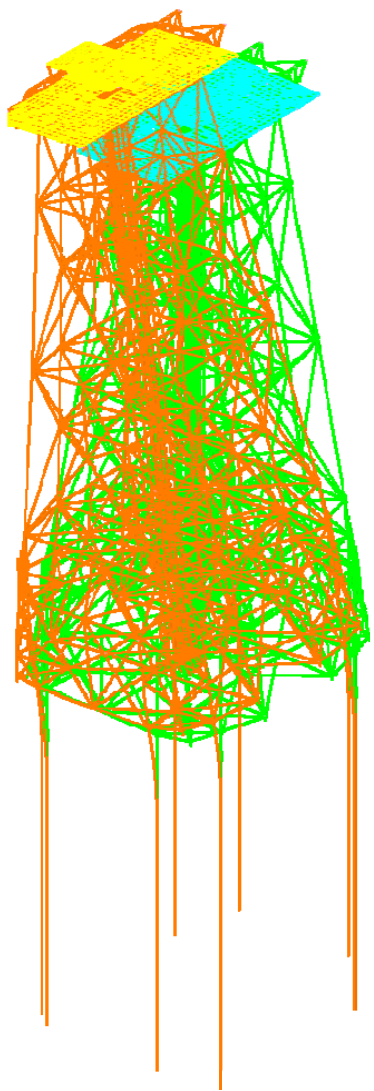

(a)

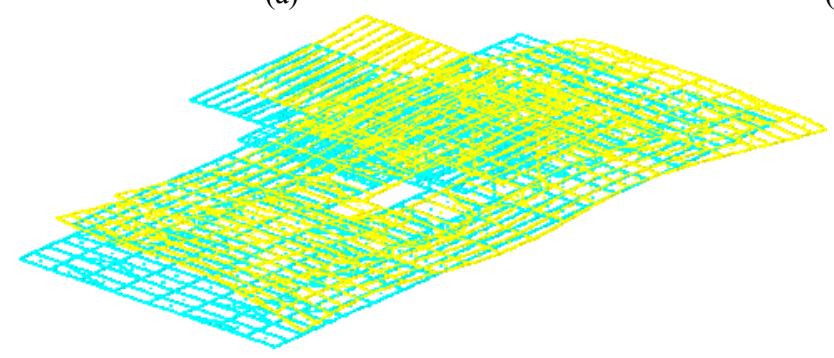

(d)

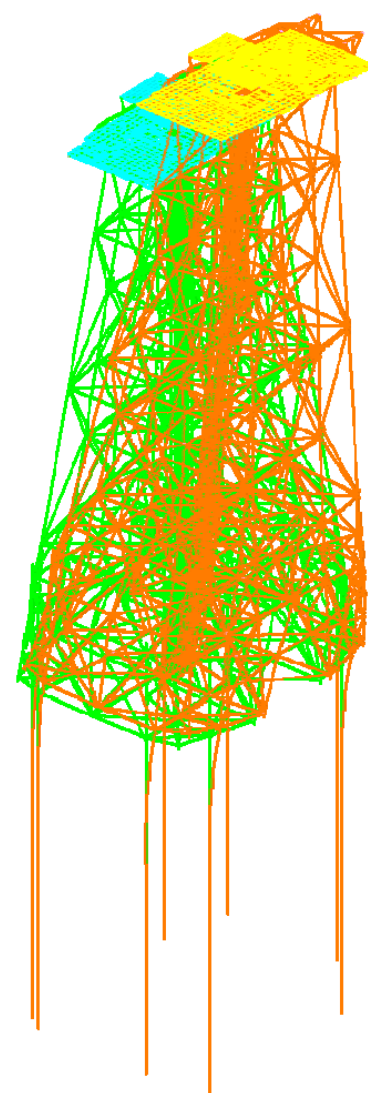

(b)

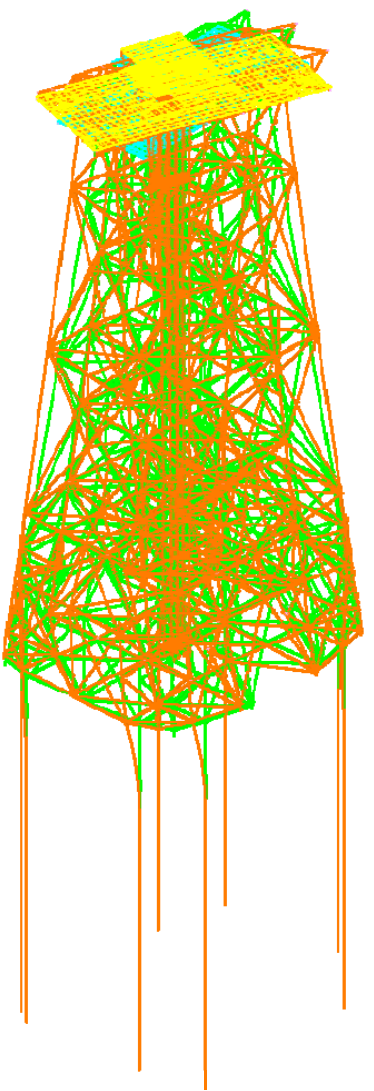

(c)

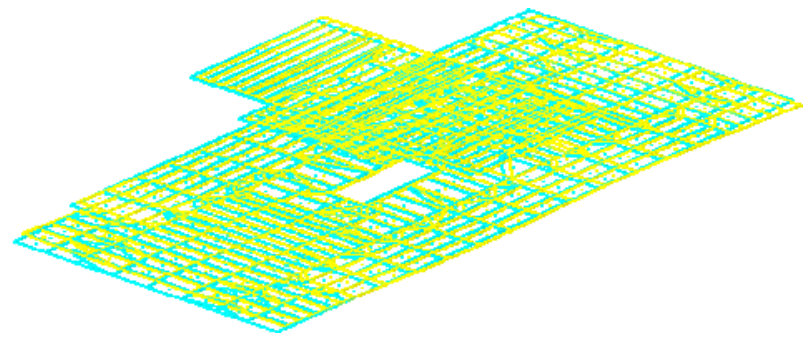

(e)

Fig. 4: Vibration modes of the investigated structural system: (a) 1st vibration mode: $f_{01}=0.67 \mathrm{~Hz}$; (b) 2nd vibration mode: $f_{02}=0.71 \mathrm{~Hz}$; (c) 3rd vibration mode: $f_{03}=1.20 \mathrm{~Hz}$; (d) 8th vibration mode: $f_{08}=1.99 \mathrm{~Hz}$; (e) 17th vibration mode: $f_{17}=2.61$ Hz.

structural system are shown in Fig. 4.

Results of Fig. 4 and Table 3 show that the three first vibration modes of the structure exhibited a predominance of displacements related to the steel jacket system. In the 1 st vibration mode, there is a predominance of translational displacements towards 
the $y$-axis in the finite element model. In the 2nd vibration mode, a predominance of translational effects towards the $\mathrm{x}$-axis of the numerical model was observed. The third vibration mode presented a predominance of torsional effects on the steel jacket system with respect to the vertical z-axis.

Flexural effects were predominant in the steel deck plate (upper and lower) beginning at the eighth vibration mode $\left(f_{08}=1.99 \mathrm{~Hz}\right.$, Vibration Mode 8, Figure 4 and Table 3). It is important to emphasize that torsional effects on the steel deck were present starting from higher mode shapes (Table 3).

\section{Structural System Dynamic Response}

This work evaluates the steel platform's performance in terms of vibration serviceability effects by considering the impacts produced by mechanical equipment (i.e., rotating machinery). This strategy was considered given that unbalanced rotors generate vibrations that may damage their components and supports and produce dynamic actions that could induce the steel deck plate system to reach high vibration levels causing human discomfort.

This way, a forced vibration analysis is performed using the developed finite element model [1, 2]. The results are obtained in terms of the structural system displacements, velocities and peak accelerations.

The modal damping ratio adopted in this analysis for the first and second vibration modes was equal to $0.5 \%(\xi=0.005)[5,9,11]$. This modal damping ratio takes into account the existence of few elements in the investigated system that contributes to structural damping $[5,9,11]$.

In this analysis, the simultaneous operation of three machines on the steel deck was considered. The nodes of the application of the dynamic loads in this situation are shown in Fig. 5. With respect to human comfort, selected nodes of the finite element model were chosen near to the equipment to evaluate the steel deck dynamic response (displacements, velocities and accelerations), as illustrated in Fig. 5.

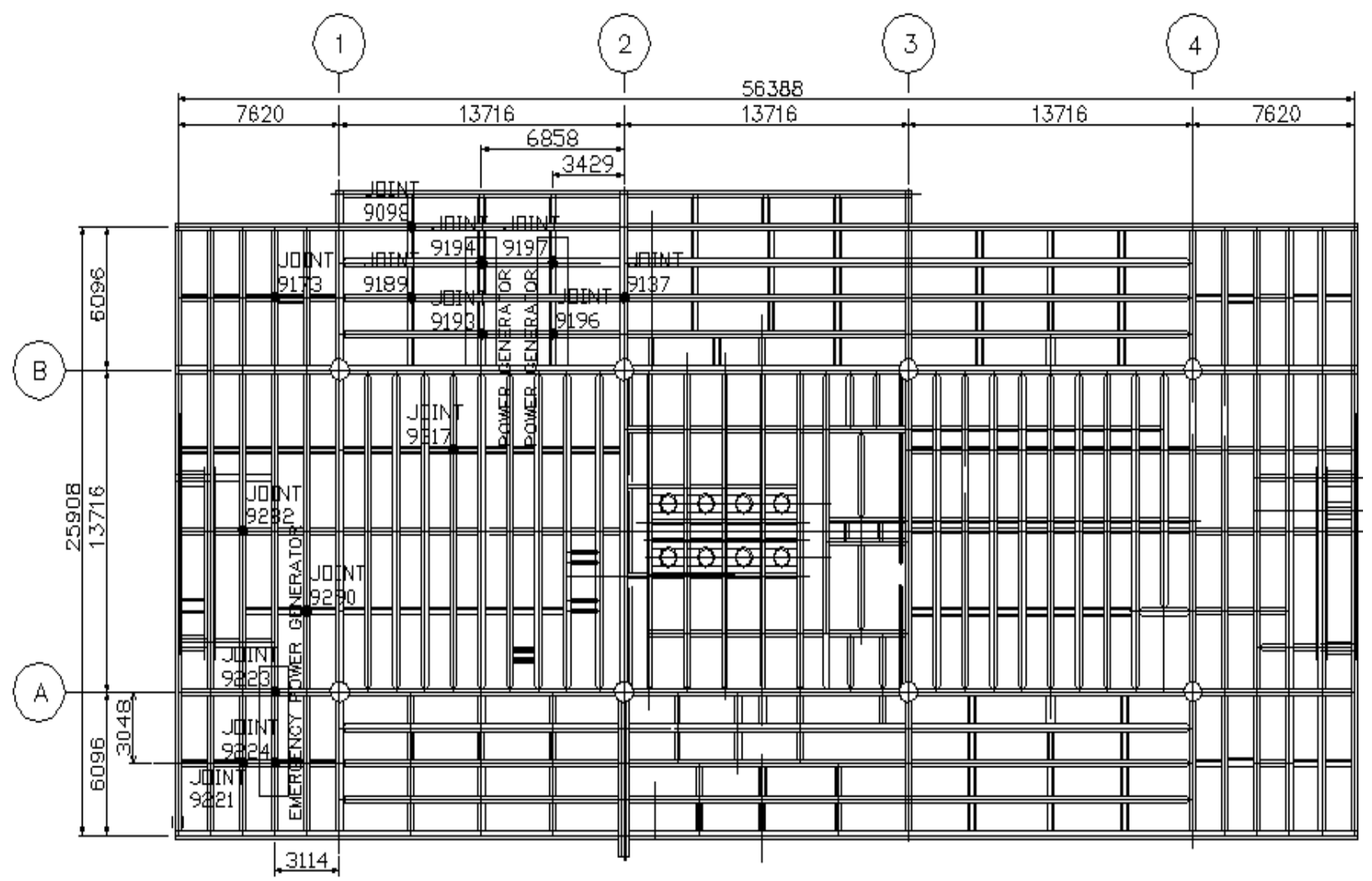

Fig. 5 Selected nodes for application of the dynamic loadings and analysis of the dynamic structural response. 
The analysis results were compared with limit values from the perspective of the structure, the operation of machinery and human comfort provided by international design recommendations [5-9]. It must be emphasized that only the structural system's steady-state response was considered in this investigation.

The frequency integration interval used in the numerical analysis was $0.01 \mathrm{~Hz}(\Delta \omega=0.01 \mathrm{~Hz})$. It was verified that the frequency integration interval accurately simulated the dynamic characteristics of the structural system and the representation of the proposed dynamic loading $[1,2]$.

Tables 4 to 6 present the vertical translational displacements, velocities and accelerations related to specific locations on the steel deck and near to the mechanical equipment (Fig. 5). These displacements were calculated when the combined dynamic loadings (rotor and gear) were considered.
These values were obtained numerically with the aid of the proposed computational model and were then compared with the limiting values proposed by design code recommendations [5-9]. Once again, it must be emphasized that only the structural system's steady state response was considered in this investigation.

In sequence, Fig. 6 shows the response spectra of the vertical translational displacements for the supports and rotors and for particular nodes of the steel deck of the platform in the frequency domain. Only two graphs are presented in the paper, given that Fig. 6 represents, in general, the dynamic response of the investigated structural system. Based on the structure dynamic response, the peak of interest for the forced vibration numerical analysis associated with the excitation frequency of the equipment $(f=30$ $\mathrm{Hz}$ ) is indicated in Fig. 6.

Allowable amplitudes are generally specified by the

Table 4 Vertical displacements: combined dynamic loading (driving).

\begin{tabular}{lll}
\hline Rotor support (Node: 9194$)(\mu \mathrm{m})$ & Rotor support (Node: 9197$)(\mu \mathrm{m})$ & $\begin{array}{l}\text { Rotor support }(\text { Node: } 9224)(\mu \mathrm{m}) \\
(\mu \mathrm{m})\end{array}$ \\
\hline 54 & 446 & 7 \\
Gear support (Node: 9193$)(\mu \mathrm{m})$ & Gear support (Node: 9196$)(\mu \mathrm{m})$ & Gear support (Node: 9223$)(\mu \mathrm{m})$ \\
77 & 432 & 38
\end{tabular}

*Limit for vibration of high speed machines (> $1500 \mathrm{rpm})[6]$.

Table 5 Velocities: combined dynamic loading (driving).

\begin{tabular}{llll}
\hline Rotor support (Node: 9194$)(\mathrm{mm} / \mathrm{s})$ & Rotor support (Node: 9197) $(\mathrm{mm} / \mathrm{s})$ & Rotor support (Node: 9224) (mm/s) & $\begin{array}{c}\lim ^{*} \\
(\mathrm{~mm} / \mathrm{s})\end{array}$ \\
\hline 10.18 & 84.12 & 11.89 & 0.70 to 2.80 \\
Gear support (Node: 9193$)(\mathrm{mm} / \mathrm{s})$ & Gear support (Node: 9196$)(\mathrm{mm} / \mathrm{s})$ & Gear support (Node: 9223$)(\mathrm{mm} / \mathrm{s})$ & \\
14.49 & 81.46 & 7.27 & \\
\hline
\end{tabular}

*Tolerable velocity for electrical motors [6].

Table 6 Accelerations: combined dynamic loading (driving).

\begin{tabular}{lllll}
\hline $\begin{array}{l}\text { Steel deck (Node: } 9098) \\
\left(\mathrm{m} / \mathrm{s}^{2}\right)\end{array}$ & $\begin{array}{l}\text { Steel deck (Node: } 9137) \\
\left(\mathrm{m} / \mathrm{s}^{2}\right)\end{array}$ & $\begin{array}{l}\text { Steel deck (Node: } 9173) \\
\left(\mathrm{m} / \mathrm{s}^{2}\right)\end{array}$ & $\begin{array}{l}\text { Steel deck (Node: } 9189) \\
\left(\mathrm{m} / \mathrm{s}^{2}\right)\end{array}$ & $\begin{array}{l}\mathrm{a}_{\text {lim }}{ }^{*} \\
\left(\mathrm{~m} / \mathrm{s}^{2}\right)\end{array}$ \\
\hline 5.62 & 6.16 & $\begin{array}{l}4.67 \\
27.33\end{array}$ & $\begin{array}{l}\text { Steel deck (Node: } 9290) \\
\left(\mathrm{m} / \mathrm{s}^{2}\right)\end{array}$ & $\begin{array}{l}\text { Steel deck (Node: } 9317) \\
\left(\mathrm{m} / \mathrm{s}^{2}\right)\end{array}$ \\
$\begin{array}{l}\text { Steel deck (Node: } 9221) \\
\left(\mathrm{m} / \mathrm{s}^{2}\right)\end{array}$ & $\begin{array}{l}\text { Steel deck (Node: } 9282) \\
\left(\mathrm{m} / \mathrm{s}^{2}\right)\end{array}$ & 11.77 & 0.61 & 0.315 to 1.0 \\
11.62 & 8.19 & & \\
\hline
\end{tabular}

*Acceptable acceleration values for human comfort [7]. 


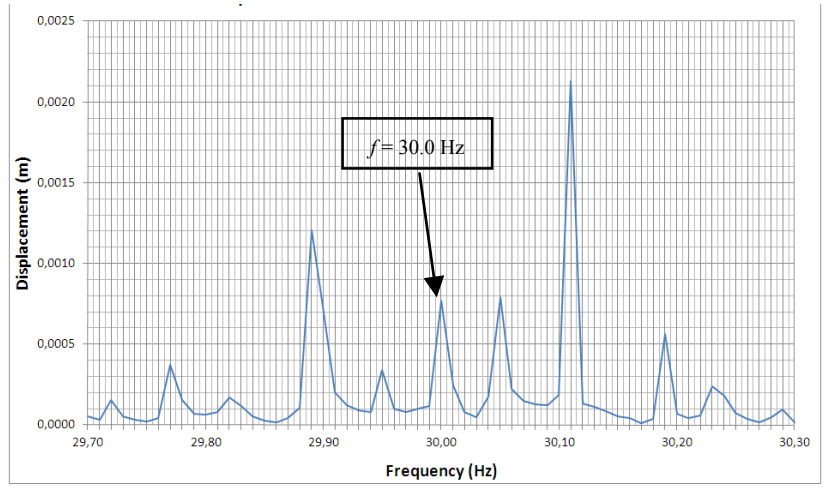

(a)

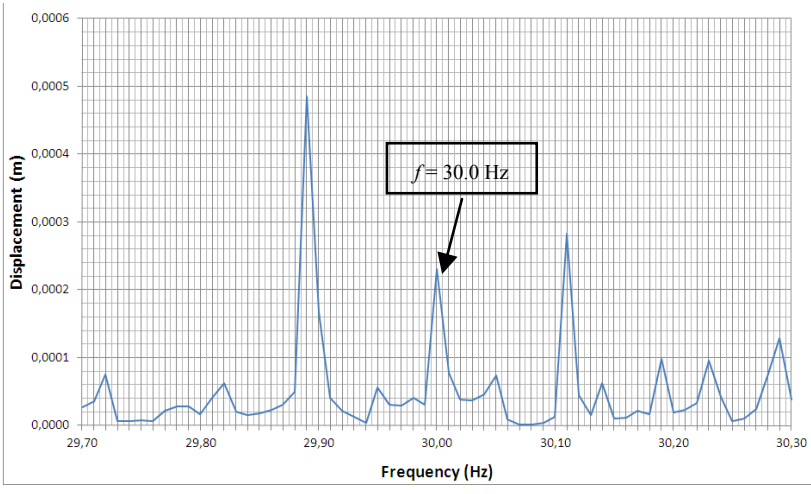

(b)

Fig. 6 Vertical displacements response spectra of the selected nodes of the steel deck near the equipment: (a) Node 9189; (b) 9282.

manufacturer of the machinery. When the manufacturer's data do not indicate allowable amplitudes, design guide recommendations [6, 7] are used to determine these limiting values for machinery performance (Table 4).

The maximum amplitude value calculated at the base of the driving support (Node 9197: Fig. 5) on the platform steel deck was equal to $446 \mu \mathrm{m}$ (i.e., 0.446 $\mathrm{mm}$ or $0.0446 \mathrm{~cm})$, indicating that the recommended limit value was violated and that the machinery performance can be considered inadequate $(0.446$ $\mathrm{mm}>0.06 \mathrm{~mm}$, see Table 4) [6].

The maximum velocity value calculated at the base of the driving support (Node 9197: Fig. 5) on the platform steel deck was equal to $84.12 \mathrm{~mm} / \mathrm{s}$ (Table 5). The allowable velocity considering the ideal condition of machinery performance is within the range of 0.7 $\mathrm{mm} / \mathrm{s}$ to $2.8 \mathrm{~mm} / \mathrm{s}$ [6], as presented in Table 5. This velocity is not in agreement with those proposed by the design codes $(84.12 \mathrm{~mm} / \mathrm{s}>2.8 \mathrm{~mm} / \mathrm{s})$ [6], violating the recommended limits.

Individuals who are temporarily working near the driving support could be affected to various degrees (human discomfort). The allowable acceleration value when human comfort is considered [7] is within the range of $0.315 \mathrm{~m} / \mathrm{s}^{2}$ to $1.0 \mathrm{~m} / \mathrm{s}^{2}$, as presented in Table 6 . The peak acceleration value calculated on the platform steel deck (Node 9189: Fig. 5) was equal to $27.33 \mathrm{~m} / \mathrm{s}^{2}$ (Table 6). This way, this peak acceleration value violates the recommended limits proposed by the design codes $\left(27.33 \mathrm{~m} / \mathrm{s}^{2}>1.0 \mathrm{~m} / \mathrm{s}^{2}\right)$ [7], causing human discomfort.

Considering the frequency domain results presented in Fig. 6, which shows the production platform steel deck structural dynamic response, it is possible to note the existence of several energy transfer areas with several energy transfer peaks. The peak of interest for the forced vibration numerical analysis associated with the excitation frequency of the equipment $(f=30$ $\mathrm{Hz}$ ) is clearly indicated in Fig. 6.

Based on the numerical results obtained with the present investigation, based on the time and frequency domain analysis, it was clearly demonstrated that the investigated structural model exhibited problems due to excessive vibration and also human discomfort.

\section{Conclusions}

This study investigated the dynamic behaviour of an oil production platform constructed of steel and located in the Santos Basin, São Paulo/SP, Brazil. The structural model consisted of two steel decks with a total area of $1,915 \mathrm{~m}^{2}$ (upper deck: $445 \mathrm{~m}^{2}$, and lower deck: $1,470 \mathrm{~m}^{2}$ ), supported by vertical sections made of tubular steel members (steel jacket) and piled into the seabed, when subjected to impacts produced by mechanical equipment (rotating machinery). The main objective of the study was to assess the dynamic impacts of the electrical generators and compressors 
on the steel deck structure.

It was concluded that the oil production platform displacements response spectra presented several energy transfer areas with several energy transfer peaks. This way, based on the displacements, velocities and peak acceleration values, obtained on the structural system steady-state response, it was possible to evaluate the structural model performance in terms of human comfort, the maximum tolerances of the mechanical equipment and the vibration serviceability limit states of the structure, based on the design code recommendations.

The results obtained throughout this investigation indicated that the platform steel deck analysed in this work violated the human comfort criteria, as well as its vibration serviceability limit states, inducing that individuals working temporarily near the machinery could be affected by human discomfort.

On the other hand, considering the machinery performance, it was also concluded that the platform steel deck design, should be revaluated, due to the fact that the displacements and velocities values related to the machinery supports were very high and violated the recommended limits proposed by design codes.

Finally, the authors would like to emphasize that further investigation will consider the study of vibration reducing techniques like base isolation or energy absorbing instrumentation at machine foundations, aiming to improve vibration performance of the investigated structural system.

\section{Acknowledgments}

The authors gratefully acknowledge the support for this work provided by the Brazilian Science Foundations: CAPES, CNPq and FAPERJ.

\section{References}

[1] Rimola, B. D. 2010. “Análise Dinâmica de Plataformas de Aço a partir da Consideração do Efeito da Interação Solo-Estrutura." M.Sc. dissertation, Civil Engineering Post-graduate Programme, PGECIV, State University of Rio de Janeiro, UERJ, Rio de Janeiro/RJ, Brazil. (in Portuguese)
[2] Rimola, B. D., Da Silva, J. G. S., Sieira, A. C. C. F., De Lima, L. R. O., and Neves, L. F. da C. 2010. "Vibration Analysis of a Production Platform Induced by Mechanical Equipments." In Proceedings of The Tenth International Conference on Computational Structures Technology, CST 2010, Valência, Spain, 1-12.

[3] Winkler, E. 1867. Die Lehre von Elastizitat und Festigkeit (On Elasticity and Fixity). Prague: Dominicus. (in German)

[4] GTSTRUDL. 2009. Structural Design \& Analysis Software. Release 29.1. Madison, Alabama: GTSTRUDL.

[5] CEB 209/91. 1991. "Vibration Problems in Structures-Practical Guidelines". Bulletin dinformation $\mathrm{N}^{\circ} 209$

[6] ISO 1940-1. 2003. Mechanical Vibration. Balance Quality Requirements for Rotors in a Constant (Rigid) State. Part 1: Specification and Verification of Balance Tolerances. ISO.

[7] ISO 2631-1. 1997. Mechanical Vibration and Shock. Evaluation of Human Exposure to Whole-Body Vibration. Part 1: General Requirements. ISO.

[8] ISO 2631-2. 1989. Mechanical Vibration and Shock. Evaluation of Human Exposure to Whole-Body Vibration. Part 2: Human Exposure to Continuous and Shock-Induced Vibrations in Buildings (1 to 80Hz). ISO.

[9] Murray, T. M., Allen, D. E., and Ungar, E. E. 2003. Floor Vibration due to Human Activity, Steel Design Guide Series. Chicago, USA: AISC (American Institute of Steel Construction).

[10] Srinivasulu, P., and Vaidyanathan, C. V. 1976. Handbook of Machine Foundations. New Delhi: McGraw-Hill.

[11] Bachmann, H., Ammann, W. J., Deischl, F., Eisenmann, J., Floegl, J., Hirsch, G. H., et al. 1995. Vibration Problems in Structures. Practical Guidelines. Basel (Switzerland): Institut für Baustatik und Konstruktion, Birkhäuser.

[12] Zhou, S., and Shi, J. 2001. "Active Balancing and Vibration Control of Rotating Machinery: A Survey." The Shock and Vibration Digest 33 (4): 361-71.

[13] Da Silva, E. L. 2004. "Dinâmica de Rotores: Modelo Matemático de Mancais Hidrodinâmicos." M.Sc. dissertation, Federal University Paraná. Paraná, PR, Brasil. (in Portuguese)

[14] Milet, R. R. 2006. "Análise Comparativa de Métodos de Cálculo para Fundações de Máquinas.” M.Sc. dissertation, Civil Engineering Post-graduate Programme, Federal University of Pernambuco, UFPE, Pernambuco, PE, Brazil. (in Portuguese)

[15] De Souza, M. G., Cicogna, T. R., and Chiquito, A. J. 2007. "Excitação dos Modos Normais de um Sistema Usando um Motor Desbalanceado." Revista Brasileira de 
de Física 29 (1): 5-10. (in Portuguese)

[16] Assunção, T. M. R. C. 2009. "Considerações Sobre Efeitos Dinâmicos e Carregamentos Induzidos por Fontes de Excitação em Estruturas." M.Sc. dissertation, Civil Engineering Post-graduate Programme, Federal University of Minas Gerais, UFMG, Minas Gerais, MG, Brazil. (in Portuguese)

[17] Genta, G. 2012. Vibration of Structures and Machines:
Practical Aspects. New York: Springer Science \& Business Media.

[18] Dias Junior, M. 2009. "Dinâmica de Rotores." In Proceedings of IV Congresso da Academia Trinacional de Ciências, Foz do Iguaçu, Paraná/PR, Brazil. (in Portuguese)

[19] Terzaghi, K. 1955. "Evaluation of Coefficients of Subgrade Reaction." Géotechnique 4 (4): 297-326. 